\title{
Envenomation by Trimeresurus stejnegeri stejnegeri: clinical manifestations, treatment and associated factors for wound necrosis
}

\author{
Liao-Chun Chiang ${ }^{1,2,3,4,5}$ @ , Wei-Jen Tsai ${ }^{4}$, Po-Yu Liu ${ }^{6,7}$, Cheng-Hsuan Ho ${ }^{2,8}$, Hung-Yuan Su9,10, Chih-Sheng Lai ${ }^{11}$, \\ Kuo-Lung Lai ${ }^{12}$, Wen-Loung Lin ${ }^{13}$, Chi-Hsin Lee ${ }^{14,15,16}$, Yi-Yuan Yang ${ }^{14,15,16} \mathbb{0}$, Uyen Vy Doan ${ }^{17}$, Tri Maharani ${ }^{18}$, \\ Yan-Chiao Mao 2,3,4,5,* ([) \\ ${ }^{1}$ National Tsing Hua University, College of Life Sciences, Hsinchu, Taiwan. \\ ${ }^{2}$ School of Medicine, National Defense Medical Center, Taipei, Taiwan. \\ ${ }^{3}$ Division of Clinical Toxicology, Department of Emergency Medicine, Taichung Veterans General Hospital, Taichung, Taiwan. \\ ${ }^{4}$ Division of Clinical Toxicology and Occupational Medicine, Department of Internal Medicine, Taipei Veterans General Hospital, Taipei, Taiwan. \\ ${ }^{5}$ Institute of Environmental and Occupational Health Sciences, School of Medicine, National Yang-Ming University, Taipei, Taiwan. \\ ${ }^{6}$ Division of Infection, Department of Internal Medicine, Taichung Veterans General Hospital, Taichung, Taiwan. \\ ${ }^{7}$ Rong Hsing Research Center for Translational Medicine, National Chung Hsing University, Taichung, Taiwan. \\ ${ }^{8}$ Department of Emergency Medicine, Tri-Service General Hospital, Taipei, Taiwan. \\ 9 Department of Emergency Medicine, E-Da Hospital, Kaohsiung, Taiwan. \\ 10 The School of Chinese Medicine for Post Baccalaureate, I-Shou University, Kaohsiung, Taiwan. \\ ${ }^{11}$ Division of Plastic and Reconstructive Surgery, Department of Surgery, Taichung Veterans General Hospital, Taichung, Taiwan. \\ ${ }^{12}$ Division of Allergy, Immunology and Rheumatology, Department of Internal Medicine, Taichung Veterans General Hospital, Taichung, Taiwan. \\ 13 Taichung Wildlife Conservation Group, Taichung, Taiwan. \\ ${ }^{14}$ School of Medical Laboratory Science and Biotechnology, College of Medical Science and Technology, Taipei Medical University, Taipei, Taiwan. \\ ${ }^{15}$ Graduate Program in Medical Biotechnology, College of Medical Science and Technology, Taipei Medical University, Taipei, Taiwan. \\ ${ }^{16}$ Core Laboratory of Antibody Generation and Research, Taipei Medical University, Taipei, Taiwan. \\ 17 Department of Clinical Toxicology, Cho Ray Hospital, Ho Chi Minh City, Vietnam. \\ ${ }^{18}$ Department of Emergency Medicine, Daha Husada Hospital, Kediri, East Java, Indonesia.
}

\section{Keywords:}

Trimeresurus stejnegeri stejnegeri

Snakebites

Snake antivenom

Chinese green tree viper

Stejneger's bamboo pitviper

\begin{abstract}
Background: Trimeresurus stejnegeri stejnegeri bite induces tissue swelling, pain, thrombocytopenia, rhabdomyolysis, and acute renal failure. However, the incidence of coagulopathy, factors associated with wound necrosis, and the appropriate management of this condition have not been well characterized yet. Materials: This study included patients bitten by T. s. stejnegeri that were admitted to the study hospitals from 2001 to 2016. Patient characteristics, laboratory data, and management approaches were compared in victims with and without wound necrosis. Results: A total of 185 patients were evaluated: three patients (1.6\%) were asymptomatic; whereas tissue swelling and pain, local ecchymosis, wound necrosis, coagulopathy, thrombocytopenia, rhabdomyolysis, and renal impairment were present in $182,53,13,15,10,1$, and 3 patients, respectively. One
\end{abstract}

* Correspondence: doc1385e@gmail.com https://doi.org/10.1590/1678-9199-JVATITD-2020-0043 Received: 31 March 2020; Accepted: 02 September 2020; Published online: 18 September 2020 
patient died from coagulopathy and hemorrhagic shock. Antivenom was administered to all envenomed patients at a median time of $1.8 \mathrm{~h}$ after the bite. The median total dose of antivenom was five vials. Chi-square analysis showed that bitten fingers, using cold packs during first aid, presence of bullae or blisters, lymphangitis or lymphadenitis, local numbness and suspected infection to be significantly associated with wound necrosis. After adjustment using a multivariate logistic regression model, only cold packs as first aid, bulla or blister formation, and wound infection remained significant. Conclusions: The main effects of T.s. stejnegeri envenomation are tissue swelling, pain, and local ecchymosis. We do not recommend the use of cold packs during first aid to reduce wound pain, as this may be a risk factor for wound necrosis. In addition, patients with bulla or blister formation should be carefully examined for subsequent wound necrosis. Antiplatelet use may worsen systemic bleeding. No severe rhabdomyolysis or renal failure was observed in this large case series, we therefore considered that they were not prominent effects of T. s. stejnegeri bite.

\section{Background}

Six venomous snakes are considered medically important in Taiwan: Trimeresurus stejnegeri stejnegeri, Protobothrops mucrosquamatus, and Deinagkistrodon acutus in the Crotalinae subfamily; Daboia siamensis in the Viperinae subfamily; and Naja atra and Bungarus multicinctus multicinctus in the Elapidae family [1]. More than $70 \%$ of the 1000 snake envenomations per year in this country are caused by the former two species [1,2]. T. s. stejnegeri is the only green pit viper in Taiwan, also found in India, Nepal, southern China, Vietnam and, possibly, Myanmar [3]. Its bite induces tissue swelling and pain, thrombocytopenia, rhabdomyolysis, and acute renal failure [4]. However, the severity of these symptoms has not been reported in previous studies [4]. Furthermore, the coagulopathy, high proportion (20\%) of acute compartment syndrome and fasciotomy after bite [5], and the potential risk factors associated with wound necrosis have not been well established. The Taiwan government produces the only globally available antivenom for T. s. stejnegeri bites. As of 1999, the Taiwan Poison Control Center (PCC) suggests that 1 to 2 vials of specific antivenom should be administered to an envenomed patient. These guidelines, however, have not been scrutinized. In this study, we retrospectively analyzed data from 185 patients who were treated at two medical centers. The objective of this study was to facilitate a better understanding of the clinical manifestations and management approaches of T. s. stejnegeri bites among first-line clinicians.

\section{Materials}

\section{Study population}

Eligible patients were those admitted to Taichung Veterans General Hospital (VGH-TC) and Taipei Veterans General Hospital (VGH-TP) between January 2001 and September 2016. Possible cases of T. s. stejnegeri bite were identified by searching computer databases at VGH-TC and VGH-TP using the keyword "bamboo snake," "Viridovipera stejnegeri" (previous name), and "Trimeresurus stejnegeri" in both English and Chinese, and these medical records carefully reviewed. Definite cases were classified by those diagnosed by examining the culprit snake, and suspected cases were classified by those diagnosed by having the patient identify the snake in a picture. Patients with snakebites for whom the culprit snake could not be identified, were excluded. Of note, some of the study population overlapped with a previous study reporting on a different time period [4].

The following data were extracted: sex, age, body part that was bitten, location at which the bite occurred, first aid used, clinical manifestation, laboratory finding, and management, including antivenom skin sensitivity test, adverse reaction to antivenom administration, time after bite to administration of antivenom, dosage of antivenom, indication for surgery, time after bite to first and last surgery, type of surgery, hospital stay, and follow-up period.

\section{Definition of variable}

We extracted these variables from medical charts. If no anomaly was mentioned in the case notes, we assumed that none was present.

\section{Local sign or symptom}

The degree of swelling, measured using a modification of Blaylock's classification [6], was categorized as minimal (local swelling at the bite site), mild (swelling involving the whole hand or foot), moderate (swelling involving the forearm up to the elbow or the leg up to the knee), or severe (swelling extending to the whole arm, thigh, or the area above). Acute compartment syndrome (ACS) was diagnosed when typical signs and symptoms and an intracompartmental pressure $>$ $30 \mathrm{mmHg}$ were documented [7]. Cases with only clinical signs and symptoms suggestive of ACS, without measurements of intracompartmental pressure, were classified as suspected ACS. Local numbness was described as effects that did not extend beyond the affected limb. Lymphangitis was clinically identified 
as a red line originating from the wound, whereas swollen tender lymph glands draining the affected area denoted lymphadenitis $[8,9]$. We used the same criteria for defining wound infection following snakebites as that used in previous studies $[9,10]$, requiring at least two of the following three criteria: (1) onset of new or increasing pain, (2) localized erythema or swelling at the bite site (both of which were defined as an increase in severity if they occurred after the peak period and initial resolution of envenomation signs and symptoms), and (3) purulence at the bite site. The presence of fever (temperature $\geq 38^{\circ} \mathrm{C}$, measured by tympanic thermometer) together with at least one of these three criteria also met the definition of a wound infection. If a patient underwent surgery, only pre-operative fever was included in the analysis. A wound discharge bacterial culture was performed when infection was suspected in a snakebite wound, and blood culture was performed during febrile episodes. The culture sampling technique has been described in the literature [11].

\section{Systemic signs or symptoms}

When the patients were admitted to hospital, they all underwent blood tests, including those to determine blood cell counts, prothrombin time (PT; international normalized ratio, INR), activated partial thromboplastin time (aPTT), creatine kinase (CK), and serum creatinine levels. These tests were performed repeatedly as required. If multiple test results were available, the most abnormal data were included in the analysis; if there were no abnormal data, data from the first test were included in the analysis. Coagulopathy was defined as INR $>1.4$ (the upper limit of reference range in study hospitals) or aPTT $>$ $35 \mathrm{~s}$ [12]. Thrombocytopenia was defined as platelet level $<150$ $\times 10^{9} / \mathrm{L}$ [13]. D-Dimer elevation was defined as a value $\geq 0.55$ fibrinogen equivalent unit (FEU) mg/L [12]. Hypofibrinogenemia was defined as fibrinogen antigen levels $<200 \mathrm{mg} / \mathrm{dL}$ (reference range: $200-400 \mathrm{mg} / \mathrm{dL}$ ). Rhabdomyolysis was defined as CK levels $>1000 \mathrm{U} / \mathrm{L}$, and renal impairment was defined as serum creatinine levels $>1.4 \mathrm{mg} / \mathrm{dL}$ [14].

\section{Outcome measurement}

Antivenom skin tests were performed according to manufacturer instructions. Early adverse reactions to antivenom, including anaphylaxis and urticaria, were defined as described in a previous study [15]. Late adverse reactions, such as serum sickness, were characterized by the presence of at least three of the following symptoms: fever, erythematous rash/urticaria, myalgia/arthralgia, headache, malaise, and nausea/vomiting 5-20 days post-antivenom treatment after carefully excluding infectious etiology [16].

\section{Statistical analysis}

To identify the potential risk factors associated with wound necrosis, characteristic data of patients with and without wound necrosis were compared using the Mann-Whitney U test for continuous variables and the chi-squared test or Fisher's exact test for categorical variables. Factors significantly associated with wound necrosis were then included in both univariate and multivariate logistic regression analyses and odds ratios (ORs), and relevant $95 \%$ confidence intervals (CIs) were reported. All data were analyzed using the Statistical Package for the Social Sciences, version 22.0 (2013 release; IBM Corp., Armonk, NY, USA). A two-tailed p-value $<0.05$ denoted statistical significance.

\section{Results}

\section{Characteristic data}

One hundred and eighty-five cases of T. s. stejnegeri bites, including 125 from VGH-TC and 60 from VGH-TP, were examined. There were 20 definite and 165 suspected cases, 13 with wound necrosis, and 172 without wound necrosis (Table 1). In total, 124 patients (67\%) were male. The median age was 53 years (range, 3-81). The bite occurred on a limb in all cases: 93 (50.3\%) were bitten on their fingers and $15(8.1 \%)$ on their toes. Of all patients, 33.5\% were bitten in a field (e.g., bush, forest, and near river), $28.1 \%$ were bitten during farming activities, and only $2.2 \%$ were bitten while indoors. A few patients used methods of first aid, including: topical herbal remedies to treat the wound (5.9\%); rope binding in an attempt to delay venom absorption (7.6\%); incision and suction (3.2\%); or cold packs to reduce pain $(6.5 \%)$.

\section{Local effect}

Three patients (1.6\%) were asymptomatic. Local swelling and pain were observed in all other patients. Local ecchymosis at the bite site, bullae or blisters, lymphadenitis or lymphangitis, local numbness, fever, and suspected wound infection occurred in $28.6 \%, 11.9 \%, 11.4 \%, 10.8 \%, 5.4 \%$, and $11.4 \%$ of patients, respectively. Positive bacterial cultures were noted in $6 / 12$ patients from whom cultures were obtained. Seven organisms were identified (Table 2): Staphylococcus aureus, Staphylococcus hominis, Citrobacter freundii, Enterobacter cloacae, Morganella morganii, Pseudomonas aeruginosa, and an anaerobic Veillonella sp. Each were identified in a single patient except for E. cloacae which was identified in two. Polymicrobial infection by S. aureus, E. cloacae, and Veillonella sp. was observed in one patient. Antibiotics administered before obtaining cultures included cefazolin, ceftriaxone, oxacillin, amoxicillin/clavulanic acid, clindamycin, and metronidazole.

\section{Systemic effect}

Coagulopathy was present in 15 patients (8.1\%); serial blood coagulation tests were performed in 8 of the 15 patients, and all 8 patients recovered within 1-8 days. Fresh frozen plasma (FFP) was administered in addition to the antivenom to two of these patients (one with INR $>10$ and aPTT $28.1 \mathrm{~s}$ and the other with INR $=5.5$ and aPTT $>224$ s), with favorable outcomes. One 
Table 1. Characteristic data, clinical manifestations, and laboratory findings of 185 Trimeresurus stejnegeri stejnegeri bite patients.

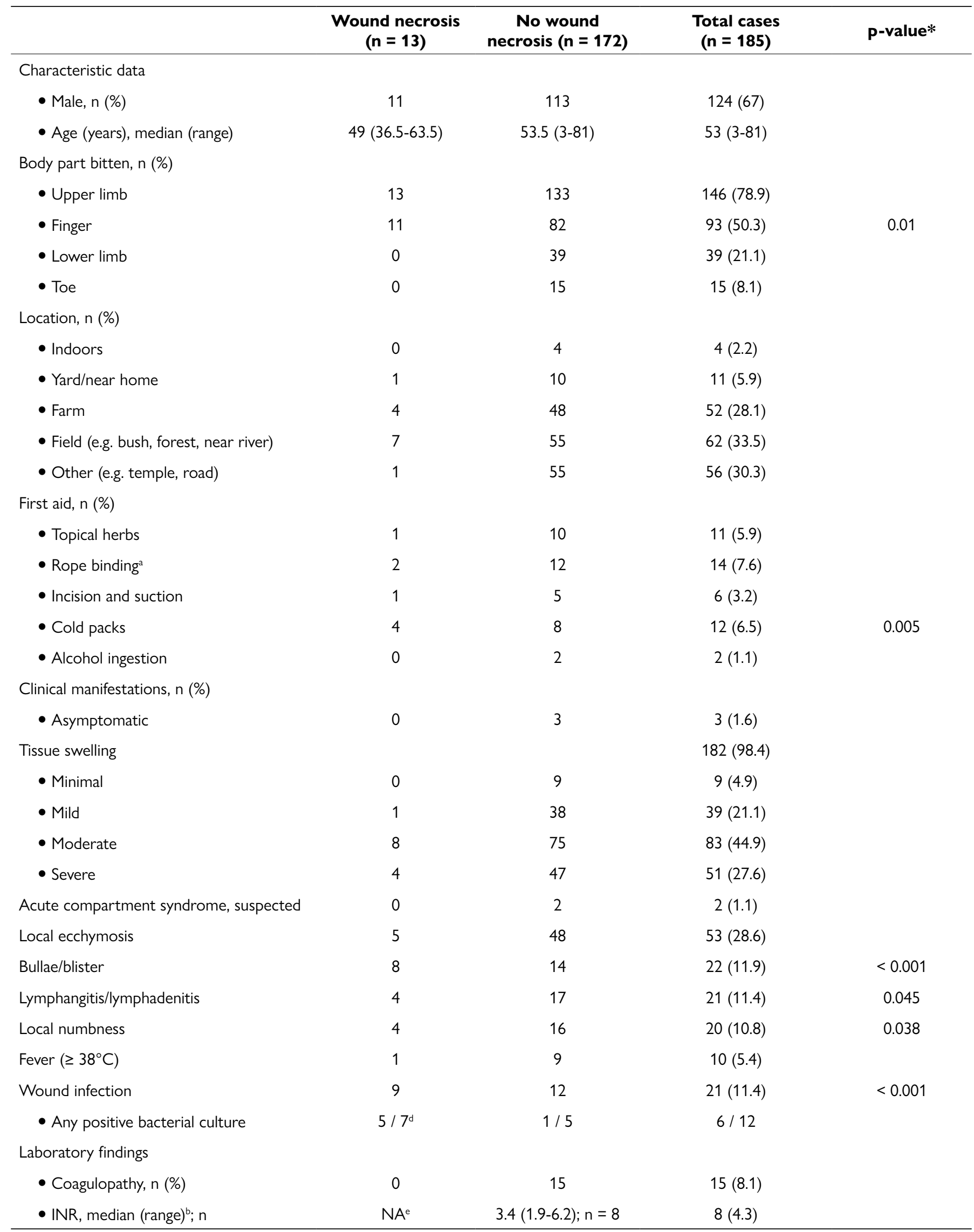


Table 1. Cont.

\begin{tabular}{|c|c|c|c|c|}
\hline & $\begin{array}{l}\text { Wound necrosis } \\
\quad(n=13)\end{array}$ & $\begin{array}{c}\text { No wound } \\
\text { necrosis }(n=172)\end{array}$ & $\begin{array}{l}\text { Total cases } \\
(n=185)\end{array}$ & p-value* \\
\hline - aPTT(s), median (range) $;$; & NA & $38(35.7-47.7) ; n=10$ & $10(5.4)$ & \\
\hline $\begin{array}{l}\text { - Thrombocytopenia }\left(\times 10^{9} / \mathrm{L}\right) \text {, } \\
\text { median (range), n }(\%)\end{array}$ & NA & $128(76-148) ; n=10$ & $10(5.4)$ & \\
\hline - D-Dimer elevation, $\mathrm{n}$ & $4 / 4$ & $21 / 23$ & $25 / 27$ & \\
\hline $\begin{array}{l}\text { - Blood level (mg FEU/L), } \\
\text { median (range) }{ }^{c}\end{array}$ & $1.1(0.7-5.1)$ & $1.3(1.1-2.5)$ & $1.1(0.7-5.1)$ & \\
\hline - Hypofibrinogenemia & $1 / 4$ & $9 / 28$ & $10 / 32$ & \\
\hline - Blood level (mg/dL), median (range) & 126 & $109(33-182)$ & $117.5(33-182)$ & \\
\hline Rhabdomyolysis & 0 & 1 & $1(0.5)$ & \\
\hline Renal dysfunction & 0 & 3 & $3(1.6)$ & \\
\hline
\end{tabular}

*Only values of statistical significance are shown. alncluding any form of rope, rubber band, or towel/clothes bindings. ${ }^{\mathrm{b}} \mathrm{One}$ patient with INR $>10$, and another two patients with aPTT > $224 \mathrm{~s}$ were excluded for calculation. ${ }^{\mathrm{C}}$ One case with D-Dimer $>10 \mathrm{FEU} \mathrm{mg/L} \mathrm{was} \mathrm{excluded} \mathrm{for} \mathrm{calculation.}{ }^{\mathrm{d} B a c t e r i a l}$ culture was obtained in seven patients and five had positive results. ${ }^{~ N A}$ : not applicable because there was no case.

Table 2. Surgical outcome or wound bacteriology in eight envenomed patients.

\begin{tabular}{|c|c|c|c|c|c|c|c|c|}
\hline $\begin{array}{l}\text { Case } \\
\text { number }\end{array}$ & $\begin{array}{c}\text { Body part } \\
\text { bitten }\end{array}$ & $\begin{array}{c}\text { Clinical } \\
\text { manifestations }\end{array}$ & $\begin{array}{l}\text { Intravenous } \\
\text { antibiotic } \\
\text { administered } \\
\text { before } \\
\text { surgery }\end{array}$ & $\begin{array}{l}\text { Type of } \\
\text { surgery }\end{array}$ & $\begin{array}{l}\text { Time after } \\
\text { bite to } \\
\text { surgery in } \\
\text { days }\end{array}$ & $\begin{array}{l}\text { Hospital } \\
\text { stay in } \\
\text { days }\end{array}$ & Outcome & $\begin{array}{l}\text { Bacterial } \\
\text { culture }\end{array}$ \\
\hline Case 1 & Finger & $\begin{array}{c}\text { Swelling and } \\
\text { pain, ecchymosis, } \\
\text { lymphadenitis/ } \\
\text { lymphangitis, bullae/ } \\
\text { blister, fever, wound } \\
\text { necrosis, wound } \\
\text { infection }\end{array}$ & $\begin{array}{l}\text { Cefazolin and } \\
\text { metronidazole }\end{array}$ & $\begin{array}{l}\text { Debridement } \\
\quad<5 \mathrm{~cm}\end{array}$ & 7 & 11.9 & Recovery & $\begin{array}{l}\text { Wound swab } \\
\text { and blood } \\
\text { culture: both } \\
\text { negative }\end{array}$ \\
\hline Case 2 & Finger & $\begin{array}{l}\text { Swelling and pain, } \\
\text { wound necrosis, } \\
\text { wound infection }\end{array}$ & $\begin{array}{c}\text { Ceftriaxone } \\
\text { and clindamycin }\end{array}$ & $\begin{array}{l}\text { Debridement } \\
\quad<5 \mathrm{~cm}\end{array}$ & 7 & 10 & Recovery & $\begin{array}{c}\text { Wound } \\
\text { swab after } \\
\text { debridement: } \\
\text { Pseudomonas } \\
\text { aeruginosa }\end{array}$ \\
\hline \multirow{4}{*}{ Case 4} & \multirow{4}{*}{ Finger } & \multirow{4}{*}{$\begin{array}{l}\text { Swelling and pain, } \\
\text { bullae/blister, wound } \\
\text { necrosis, wound } \\
\text { infection }\end{array}$} & \multirow{4}{*}{$\begin{array}{l}\text { Amoxicillin/ } \\
\text { clavulanic acid }\end{array}$} & $\begin{array}{l}\text { Debridement } \\
\quad<5 \mathrm{~cm}\end{array}$ & 3 & \multirow{4}{*}{5.9} & \multirow{4}{*}{ Recovery } & \multirow{4}{*}{$\begin{array}{l}\text { Wound swab } \\
\text { after first } \\
\text { debridement: } \\
\text { Morganella } \\
\text { morganii }\end{array}$} \\
\hline & & & & $\begin{array}{l}\text { Debridement } \\
\quad<5 \mathrm{~cm}\end{array}$ & 13 & & & \\
\hline & & & & $\begin{array}{l}\text { Debridement } \\
\quad<5 \mathrm{~cm}\end{array}$ & 21 & & & \\
\hline & & & & $\begin{array}{l}\text { Full-thickness } \\
\text { skin graft }\end{array}$ & 24 & & & \\
\hline
\end{tabular}


Table 2. Cont.

\begin{tabular}{|c|c|c|c|c|c|c|c|c|}
\hline $\begin{array}{l}\text { Case } \\
\text { number }\end{array}$ & $\begin{array}{l}\text { Body part } \\
\text { bitten }\end{array}$ & $\begin{array}{c}\text { Clinical } \\
\text { manifestations }\end{array}$ & $\begin{array}{l}\text { Intravenous } \\
\text { antibiotic } \\
\text { administered } \\
\text { before } \\
\text { surgery }\end{array}$ & $\begin{array}{l}\text { Type of } \\
\text { surgery }\end{array}$ & $\begin{array}{l}\text { Time after } \\
\text { bite to } \\
\text { surgery in } \\
\text { days }\end{array}$ & $\begin{array}{l}\text { Hospital } \\
\text { stay in } \\
\text { days }\end{array}$ & Outcome & $\begin{array}{l}\text { Bacterial } \\
\text { culture }\end{array}$ \\
\hline \multirow{3}{*}{ Case 6} & \multirow{3}{*}{ Forearm } & \multirow{3}{*}{$\begin{array}{c}\text { Swelling and pain, } \\
\text { ecchymosis, local } \\
\text { numbness, suspected } \\
\text { ACS }^{a}\end{array}$} & \multirow{3}{*}{$\begin{array}{l}\text { Cefazolin and } \\
\text { gentamicin }\end{array}$} & Fasciotomy & 0.33 & & & \multirow{3}{*}{$\begin{array}{c}\text { Not } \\
\text { performed }\end{array}$} \\
\hline & & & & $\begin{array}{l}\text { Debridement } \\
>10 \mathrm{~cm} \\
\text { and split- } \\
\text { thickness skin } \\
\text { graft }\end{array}$ & 5 & 11.8 & Recovery & \\
\hline & & & & $\begin{array}{l}\text { Revision of } \\
\text { scar }\end{array}$ & 59 & & & \\
\hline Case 7 & Finger & $\begin{array}{l}\text { Swelling and pain, } \\
\text { wound infection }\end{array}$ & No antibiotic & $\begin{array}{c}\text { Not } \\
\text { performed }\end{array}$ & - & 8.1 & Recovery & $\begin{array}{l}\text { Joint fluid: } \\
\text { Citrobacter } \\
\text { freundii }\end{array}$ \\
\hline Case 8 & Finger & $\begin{array}{l}\text { lymphadenitis/ } \\
\text { lymphangitis, bullae/ } \\
\text { blister, wound } \\
\text { necrosis, wound } \\
\text { infection }\end{array}$ & $\begin{array}{l}\text { Cefazolin and } \\
\text { metronidazole }\end{array}$ & $\begin{array}{c}\text { Not } \\
\text { performed }\end{array}$ & - & 3 & Recovery & $\begin{array}{c}\text { aureus, } \\
\text { Enterobacter } \\
\text { cloacae; } \\
\text { Veillonella sp. } \\
\text { (anaerobic) }\end{array}$ \\
\hline
\end{tabular}

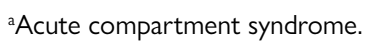

patient died due to coagulopathy ( $\mathrm{INR}=6.2$ and aPTT $>224 \mathrm{~s}$ ) and hemorrhagic shock, did not received FFP transfusion in time. Thrombocytopenia occurred in 10 patients (5.4\%), including 9 classified as mild and 1 moderate decrease in platelet levels. D-Dimer elevation and hypofibrinogenemia was present in 24/26 and 10/32 patients tested, respectively. Rhabdomyolysis and renal impairment occurred in 1 (0.5\%, highest CK level, $1679 \mathrm{U} / \mathrm{L})$ and $3(1.6 \%$, serum creatinine $1.7,2$, and $3.1 \mathrm{mg} / \mathrm{dL})$ patients, respectively. During the study period, no hemolysis, delayed systemic bleeding, or gastrointestinal effect were observed.

\section{Management and outcome}

Of the 182 envenomed patients, three patients (1.6\%) with a negative antivenom skin test developed anaphylaxis during antivenom administration presenting as generalized urticaria in all three, stridor in two, and hypotension in one, which promptly resolved upon epinephrine, antihistamine, steroid, and fluid replacement therapy (Table 3). Seven patients (3.8\%) had skin rashes without systemic reactions, however only two had a positive skin test result. The positive and negative likelihood ratios of the antivenom skin test for anaphylaxis and skin rashes were 0 and 1.1 (CI 95\% 1.1-1.2), and 3 (CI 95\% $0.9-10.5$ ) and 0.8 (CI 95\% 0.5-1.3), respectively. Ten patients experienced serum sickness after receiving a median of 10 vials of antivenom (interquartile range, IQR, 4.5-12.5). This median dosage of antivenom administration differed significantly in patients without serum sickness (median 4 vials, IQR 2-8; Mann-Whitney U test, p-value 0.041). One hundred sixty-nine patients $(92.9 \%)$ received specific antivenom within $6 \mathrm{~h}$ after the bite. The exact time of first antivenom administration could be extracted in 111 envenomed cases, and the median time elapsing between the bite and administration of antivenom was $1.8 \mathrm{~h}$ (IQR, 1.2-3.3 h). The median total dose of specific antivenom was five vials (IQR, 2-8 vials).

Surgical indications included wound necrosis with secondary infection in five patients and suspected ACS in the other one. A total of 11 surgeries were performed in these six cases, including six debridement, one fasciotomy, and two split-thickness skin graft (STSG) or full-thickness skin graft (FTSG), alongside scar revision. No finger or toe amputation was observed. Excluding the suspected ACS case, the first surgery was performed a median of 7 days after bite (IQR, 4.5-9 days), and the last was performed 24 days after bite. Two patients (1.1\%) had suspected ACS in the forearm: one underwent fasciotomy at $8 \mathrm{~h}$ post-bite, debridement and STSG on day 5, and scar revision on day 59 (hospital stay, 11.8 days), whereas the other refused surgery but recovered without complications. The median hospital stay was 2.4 days (IQR, 1.4-4 days) for all patients, including 2.2 days (IQR, 1.3-3.8 days) for unoperated patients and 9.4 days (IQR, 7.2-11.8 days) for operated patients. The median follow-up period was 8.5 days (IQR, 5-14.3 days). No case of tetanus was observed in the study.

\section{Statistical findings}

To better identify the factors associated with wound necrosis, we included only envenomed cases in the regression analysis. Univariate logistic regression showed that finger as the bite site, 
using cold packs, bullae or blister, lymphangitis or lymphadenitis, local numbness, and wound infection were significant (Table 4). Multivariate logistic regression using a forward stepwise selection model approach showed that only cold packs, bullae or blister, and wound infection were significant associated with wound necrosis. In the envenomed cases, early administration of antivenom $(<6 \mathrm{~h})$ was not shown to be associated with a lower incidence of bullae or blister formation, wound necrosis, coagulopathy, and thrombocytopenia ( $\mathrm{p}$-value $=0.055,0.235$, 0.306 , and 1 , respectively) using chi-squared analysis.

Table 3. Management of 182 Trimeresurus stejnegeri stejnegeri envenomed patients.

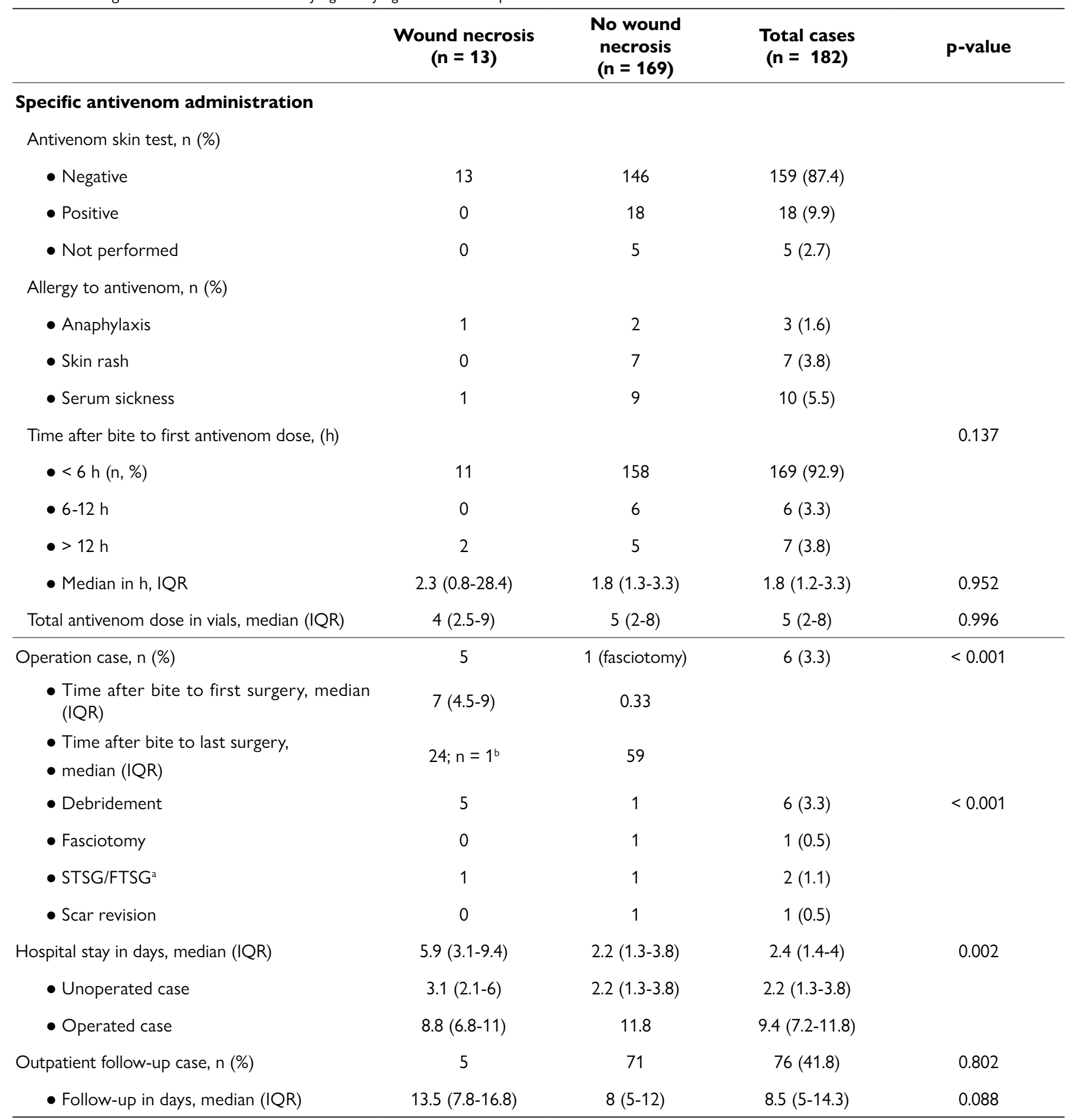

aSplit-thickness skin graft and full-thickness skin graft. ${ }^{b} \mathrm{~A}$ single case received four operations on days 3, 13, 21 (debridement), and 24 (FTSG) post-bite. 
Table 4. Logistic regression analysis of associated factors for wound necrosis in 182 envenomed patients.

\begin{tabular}{|c|c|c|c|c|}
\hline \multirow{2}{*}{ Variable } & \multicolumn{4}{|c|}{ Wound Necrosis } \\
\hline & Crude OR & P-value & Adjusted OR & p-value \\
\hline Finger as the bite site & $6.1(1.3-28.4)$ & 0.021 & - & - \\
\hline Cold packs & $8.9(2.3-35.6)$ & 0.002 & $26.5(3.4-205.6)$ & 0.002 \\
\hline Lymphangitis or lymphadenitis & $4.0(1.1-14.3)$ & 0.035 & - & - \\
\hline Local numbness & $4.3(1.2-15.4)$ & 0.027 & - & - \\
\hline
\end{tabular}

- Not significant.

\section{Discussion}

The hallmarks of T. s. stejnegeri bites are tissue swelling and pain, probably resulting from histamine release and microvascular leakage triggered by phospholipase $\mathrm{A}_{2} \mathrm{~s}\left(\mathrm{PLA}_{2} \mathrm{~s}\right)$ and other enzymes [17]. Tissue swelling can be so severe that it imitates ACS, leading to treatment by fasciotomy. The reported incidence of ACS and fasciotomy following snakebite in recent Taiwanese studies ranges from $6.6 \%$ to $39 \%[18,19]$, including $20 \%$ following T. s. stejnegeri bites [5], unlike the figures of $0.2 \%$ to $1.36 \%$ reported in worldwide studies [18] and $<1.1 \%$ in the present study. The method of diagnosing ACS was not mentioned in the study by Hsieh et al [5]. Diagnosis based on signs and symptoms is unreliable, as snake venom can induce limb edema, pain, and/or paresthesia, which confound the diagnostic accuracy of physical examination $[18,19]$. One of our two suspected ACS patients did not receive fasciotomy but recovered well with repeated antivenom therapy, and the other who received fasciotomy without repeated antivenom administration, needed revision of his scar to restore his hand function. To avoid unnecessary surgery like that reported in Taiwan, we recommend monitoring intracompartmental pressure in snakebite victims with suspected ACS $[8,20]$. Surgery should be considered when the intracompartment pressure was documented to be $>30 \mathrm{mmHg}$ or other objective criteria have been met [7,20]. Antivenom may reduce intracompartmental pressure; therefore, an adequate dose of antivenom should be administered prior to attempting decompression surgery $[8,21]$.

Wound necrosis following T. s. stejnegeri bite probably results from the cytotoxic effect of venom PLA $\mathrm{A}_{2}$ and/or secondary infection [22]. Either a local deposit of the venom which would be inaccessible to the antivenom, or a mechanism which is no longer under the direct influence of the venom like NETosis and/or oxidative stress related to the pathological amplification of the inflammatory syndrome in the continuation, even the late appearance of tissue destruction should also be considered
$[23,24]$, as this may render the antivenom therapy to be ineffective. Nevertheless, the contributing effect of cold packs has not been thoroughly examined [25]. In Taiwan, cold packing was occasionally used during first aid by snakebite patients to reduce pain [9]. Although 'cryotherapy' (soaking the whole limb in ice or ice water), is prohibited in snakebite management [26]. Placing cold packs intermittently on the bite site for pain control, was believed to be less likely to cause harm [27]. Nonetheless, the optimal temperature, frequency, and anatomic location of cold pack application has not been evaluated in snakebite management as is has for jellyfish stings [28]. Such first aid may impair tissue perfusion, causing wound necrosis, and should be discouraged until sufficient evidence is available. Bullae and blister formation was associated with wound necrosis is similar to the finding of a previous study [29], which may result from the proteolytic effect of snake venom metalloproteinases (SVMPs) at the dermal-epidermal junction [30]. From a clinical perspective, bullae or blister formation usually precedes wound necrosis in T. s. stejnegeri bite. Early removal of the bullae or blister, similar to the management of a chemical burn, may reduce the venom load at the inoculation site [31,32]. However, whether such a procedure lowers the risk of wound necrosis should be evaluated.

Chen et al. studied the bacteriology of snakebite wounds in Taiwan and found that Morganella morganii and Enterococcus spp. were the most commonly isolated pathogens. As such, they suggested amoxicillin/clavulanic acid with ciprofloxacin or piperacillin/tazobactam to treat snakebite wound infection [33]. Mao et al. further specifically investigated the bacteriology of $N$. atra bite wounds, and found that these two pathogens were primarily related to $N$. atra bite infection $[9,10]$. In our study, M. morganii and Enterococcus spp. were not commonly observed. These differences in wound bacteriology may be due to interspecies variation in the oral flora of the related snakes [10]. A higher infection rate was observed in our study compared to a previous study ( $11.4 \%$ vs $6 \%)$ [4], however we 
defined wound infection based on the criteria used by Mao et al. $[9,10]$, and it is noteworthy that $10 \%-70 \%$ of inanimate object puncture wounds develop infectious complications [34]. Based on the bacteriology findings, we suggest a first-generation cephalosporine with aminoglycoside, or sulfamethoxazole/ trimethoprim as initial antibiotics for the management of infected T. s. stejnegeri bite wounds. Prophylactic antibiotics administration is not recommended and antibiotics should be administered only when infection occurs.

T. s. stejnegeri venom consists of SVMPs (43.1\%), $\mathrm{PLA}_{2} \mathrm{~s}$ (24.5\%), snake venom serine proteases (SVSPs, $11 \%$ ), and other minor components [35]. The median lethal dose of crude venom is $2 \mu \mathrm{g} / \mathrm{g}$ intraperitoneal injection in mice [36]. SVMPs cause proteolytic degradation of extracellular matrix which normally maintains the structure and integrity of capillaries. This degradation leads to the disruption of microvessel networks, edema, and hemorrhage [35]. SVSPs are hemostatically active toxins perturbing the maintenance and regulation of both the blood coagulation cascade and the fibrinolytic feedback system at specific points [37]. PLA 2 s have evolved into extremely potent toxins, displaying myotoxic, anticoagulant, and edemainducing activities $[17,38]$. In T. s. stejnegeri venom, thrombinlike enzymes (TLEs) and $\alpha$ - and $\beta$-fibrinogenases are present [39]. TLEs are pseudo-procoagulant SVSPs [40]; in animal studies, when TLEs are administered intravenously, they induce rapid defibrinogenation via proteolytic effects on fibrinogen, forming fibrin monomers (non-cross-linked fibrin) that can be rapidly removed from the circulation either by fibrinolysis or the reticuloendothelial system, thus prolonging the coagulation time [41-43]. Alpha- and $\beta$-fibrinogenases, which are SVMPs and SVSPs, respectively, cause fibrinogenolysis and fibrinolysis, and so potentiate the effect of TLEs on net anticoagulation [39,44]. Prothrombin activation inhibitor, an acidic PLA $\mathrm{A}_{2}$, interferes with prothrombin and its activating factors via reversible binding [45]. PLA ${ }_{2}$ s and SVSPs may synergistically work to potentiate the hemorrhagic activity of SVMPs [46].

Although ecchymosis has been reported in T. s. stejnegeri bites [4], systemic bleeding is rare. In the present study we observed that ecchymosis usually occurred around the wound, probably because the coagulotoxin levels (e.g., TLEs, fibrinogenases, and plasminogen activator) are low [35,41,47], despite the high proportion of hemorrhagic SVMPs in the venom [35]. Despite this, an unfortunate incident still occurred. A 71-year-old woman who was receiving aspirin therapy for coronary artery disease sustained a T. s. stejnegeri bite on her left foot. After the bite, she had an accidental fall resulting in facial contusion, and she visited the hospital $13 \mathrm{~h}$ after envenomation. Physical examination on arrival revealed local ecchymosis around the wound in addition to leg swelling. She had clear consciousness and brain computed tomography uncovered no intracranial hemorrhage. However, coagulopathy and upper gastrointestinal bleeding occurred, therefore, five vials of antivenom were immediately administered. She died $18 \mathrm{~h}$ after hospitalization as a result of continuous gastrointestinal bleeding and shock.
Her initial blood fibrinogen level and coagulation factor 2, 7, 9 , and 10 activities were $32.5 \mathrm{mg} / \mathrm{dL}, 40 \%$ (reference range, $50-150 \%), 48.1 \%$ (65-135\%), 48.2\% (60-140\%), and 27.7\% (45$155 \%)$, respectively. Platelet count was normal. We speculated that $T$. s. stejnegeri venom influences the extrinsic coagulation pathway in addition to causing hypofibrinogenemia. In our observation, thrombocytopenia was uncommon and generally mild. The mechanism might have involved platelet aggregation/ agglutination and the action of SVMPs on the microvessel wall $[48,49]$. Antiplatelet therapy may worsen severe bleeding [50], while administration of FFP in patients with T. s. stejnegeri bite and coagulopathy may help to restore coagulation factors and reduce the risk of bleeding $[8,51]$.

Three patients experienced renal impairment, including the 71-year-old woman who died from hemorrhagic shock. Her renal impairment (serum creatinine level up to $3.1 \mathrm{mg} / \mathrm{dL}$ ) was assumed to have resulted from hypovolemia. One 80 -year-old male patient experienced transient renal impairment (serum creatinine levels up to $1.7 \mathrm{mg} / \mathrm{dL}$ ), and his serum creatinine returned to normal within 4 days after fluid replacement therapy, suggesting that the impairment was related to dehydration. Another 80 -year-old male patient who had creatinine levels of $2 \mathrm{mg} / \mathrm{dL}$, was later found to have chronic renal insufficiency through a kidney sonography. Despite the presence of myotoxic and hemolytic $\mathrm{PLA}_{2} \mathrm{~s}$ in $T$. s. stejnegeri venom $[22,48]$, no significant rhabdomyolysis, or hemolysis was observed. Although acute renal failure has been reported in T. s. stejnegeri bites, the suspected cause was not described $[4,5]$. After careful review of the medical records, we believe that significant rhabdomyolysis and severe nephrotoxicity are not typical features of $T$. s. stejnegeri envenomation.

The Taiwan government produces four types of antivenom, all of which are ammonium sulfate-precipitated $\mathrm{F}\left(\mathrm{ab}^{\prime}\right)_{2}$, fragment in lyophilized form: two bivalent specific antivenoms (one for $P$. mucrosquamatus and T. s. stejnegeri and one for N. atra and $B$. m. multicinctus), and two monovalent antivenoms (one for $D$. acutus and one for $D$. siamensis). The bivalent specific antivenom for T. s. stejnegeri and P. mucrosquamatus was determined to neutralize $26 \mathrm{mg}$ venom of $T$. s. stejnegeri per vial [36]. Based on the range amount of venom milked from a snake (0.6-30.3 $\mathrm{mg}$ ), Taiwan PCC has stated that 1-2 vials are required to treat an envenomed bite [36]. Our antivenom dosage was higher than that recommended by PCC, probably because of the higher proportion of moderate and severe swelling and finger or toe bites in our study than that in a previous study [52]. Additionally, physicians may believe that the use of antivenom accelerates recovery [53]. However, the lack of an association between early administration of antivenom and a lower incidence of certain pathological effects (i.e., bullae or blister formation, wound necrosis, coagulopathy, and thrombocytopenia) remains poorly understood.

Our findings should be evaluated in a properly designed prospective study. Additional tests of the antivenom against the enzymes related to cytotoxicity, the effect of venom on individual coagulation factors, and the ability of antivenom to neutralize the 
coagulotoxic effect specifically and determine variations in the venom components could be the initial steps to optimizing the treatment for T.s. stejnegeri bites. Although a greater proportion of patients in our study had an allergic response to antivenom in comparison with that reported during management of N. atra bite [9], there was a low incidence of anaphylaxis. In addition, neither hospital had adopted a desensitization protocol or administration of prophylactic epinephrine because of the low incidence of anaphylaxis. Our findings suggest that antivenom skin tests do not accurately predict allergic responses and may be omitted. Instead, close observation of all patients who receive antivenom is warranted [8].

\section{Limitations}

This study had limitations. First, VGH-TC, and VGH-TP are medical centers. The incidence of symptomatology as well as the management of cases may not be generalizable to all primary care facilities due to possible referral bias. Secondly, coagulation factor activities were not routinely measured and because the blood tests were usually repeated as requested by clinicians rather than at fixed time intervals, the onset, and duration of certain hematological disturbances may not have been identified. Thirdly, patients may have received several forms of treatment (e.g., wound cleansing, or topical herbal remedies) that may have altered the bacterial composition and load before bacterial culture collection. Furthermore, because the data collection was from retrospective chart review and the absence of data was recorded as the occurrence of signs or symptoms not being present, the results should be cautiously interpreted. Despite these limitations, it is the first study to specifically investigate $T$. s. stejnegeri bites, with findings that may have important clinical implications for the management of this condition.

\section{Conclusions}

The main effects of T. s. stejnegeri envenomations are tissue swelling, pain, and local ecchymosis. The factors associated with wound necrosis were cold packing as first aid, bulla and blister formation, and wound infection. With treatment using specific antivenom, life-threatening bleeding is rare, and rhabdomyolysis and nephrotoxicity are not prominent consequences of $T$. $s$. stejnegeri envenomation.

\section{Abbreviations}

ACS: acute compartment syndrome; aPTT: activated partial thromboplastin time; B. m. multicinctus: Bungarus multicinctus multicinctus; CI: confidence interval; CK: creatine kinase; $D$. acutus: Deinagkistrodon acutus; D. siamensis: Daboia siamensis; E. cloacae: Enterobacter cloacae; FEU: fibrinogen equivalent unit; FTSG: full-thickness skin graft; INR: international normalized ratio; IQR: interquartile range; $N$. atra: Naja atra; OR: odds ratio; PCC: poison control center; $\mathrm{PLA}_{2}$ : phospholipase $\mathrm{A}_{2}$; P. mucrosquamatus: Protobothrops mucrosquamatus; PT: prothrombin time; S. aureus: Staphylococcus aureus; STSG: splitthickness skin graft; SVMP: snake venom metalloproteinase; SVSP: snake venom serine protease; TLE: thrombin-like enzyme; T. s. stejnegeri: Trimeresurus stejnegeri stejnegeri; VGH-TC: Taichung Veterans General Hospital; VGH-TP: Taipei Veterans General Hospital.

\section{Availability of data and materials}

The datasets generated during and/or analyzed during the current study are available from the corresponding author on reasonable request.

\section{Funding}

Not applicable.

\section{Competing interests}

The authors declare that they have no competing interests.

\section{Authors' contributions}

The first to third authors, LCC, WJT, and PYL interpreted the clinical findings and drafted the manuscript. The second, sixth, and seventh authors, WJT, CSL, and KLL provided detailed data collection from VGH-TC and VGH-TP. The fourth, fifth, eleventh, and twelfth authors, CSH, HYS, UVD, and TM provided professional opinions and helped to examine and correct data. The eighth to tenth authors, WLL, CHL, and YYY helped to identify the snakes, correct data, and interpret venomic and antivenomic results. The correspondent author YCM designed this study, interpreted the clinical findings and revised the manuscript. All authors read and approved the final manuscript.

\section{Ethics approval and consent to participate}

The study protocol was approved by the Institutional Review Board of Taichung Veterans General Hospital (IRB, CE14202A) and of Taipei Veterans General Hospital (IRB, 2017-05-001CC).

\section{Consent for publication}

Not applicable.

\section{References}

1. Mao YC, Hung DZ. Epidemiology of Snake Envenomation in Taiwan. Gopalakrishnakone P, Faiz MA, Fernando R, Gnanathasan CA, Habib AG, Yang CC, editor's. Clinical Toxinology in Asia Pacific and Africa. Singapore: Springer. p. 3-22. 2015.

2. Chen CK, Lin CC, Shih FY, Chaou CH, Lin JCC, Lai TI, et al. Populationbased study of venomous snakebite in Taiwan. J Acute Med. 2015;5(2):3842.

3. Uetz P, Freed P, Hošek J, et al. The Reptile Database. Retrieved from http://www.reptile-database.org/. Accessed Jan 19, 2020.

4. Chen YW, Chen MH, Chen YC, Hung DZ, Chen CK, Yen DHT, et al. Differences in clinical profiles of patients with Protobothrops mucrosquamatus and Viridovipera stejnegeri envenoming in Taiwan. Am J Trop Med Hyg. 2009 Jan;80(1):28-32. 
5. Hsieh YH, Hsueh JH, Liu WC, Yang KC, Hsu KC, Lin CT, et al. Contributing factors for complications and outcomes in patients with snakebite: experience in a medical center in southern Taiwan. Ann Plast Surg. 2017 Mar;78(3 Suppl 2):S32-6.

6. Blaylock R. Antibiotic use and infection in snakebite victims. S Afr Med J. 1999 Aug;89(8):874-6.

7. Tiwari A, Haq Al, Myint F, Hamilton G. Acute compartment syndromes. Br J Surg. 2002 Apr;89(4):397-412.

8. Guidelines for the management of snake-bites. New Delhi: World Health Organization, Regional Office for South-East Asia. 2016.

9. Mao YC, Liu PY, Chiang LC, Lai CS, Lai KL, Ho CH, et al. Naja atra snakebite in Taiwan. Clin Toxicol (Phila). 2018 Apr;56(4):273-80.

10. Mao YC, Liu PY, Hung DZ, Lai WC, Huang ST, Hung YM, et al. Bacteriology of Naja atra snakebite wound and its implications for antibiotic therapy. Am J Trop Med Hyg. 2016 May 4;94(5):1129-35.

11. Bowler PG, Duerden BI, Armstrong DG. Wound microbiology and associated approaches to wound management. Clin Microbiol Rev. 2001 Apr;14(2):244-69.

12. Isbister GK, Maduwage K, Scorgie FE, Shahmy S, Mohamed F, Abeysinghe $\mathrm{C}$, et al. Venom concentrations and clotting factor levels in a prospective cohort of Russell's viper bites with coagulopathy. PLoS Negl Trop Dis. 2015 Aug;9(8):e0003968.

13. Williamson DR, Albert M, Heels-Ansdell D, Arnold DM, Lauzier F, Zarychanski $\mathrm{R}$, et al. Thrombocytopenia in critically ill patients receiving thromboprophylaxis: frequency, risk factors, and outcomes. Chest. 2013 Oct;144(4):1207-15.

14. Hung DZ, Wu ML, Deng JF, Shiau SYL, et al. Russell's viper snakebite in Taiwan: differences from other Asian countries. Toxicon. 2002 Sep;40(9):1291-8.

15. Anagnostou K, Turner PJ. Myths, facts and controversies in the diagnosis and management of anaphylaxis. Arch Dis Child. 2019 Jan;104(1):83-90.

16. Ryan NM, Kearney RT, Brown SG, Isbister GK. Incidence of serum sickness after the administration of Australian snake antivenom (ASP-22). Clin Toxicol. 2016;54(1):27-33.

17. Ouyang C, Shiau SY. Relationship between pharmacological actions and enzymatic activities of the venom of Trimeresurus gramineus. Toxicon. 1970 Aug;8(2):183-91.

18. Hsu CP, Chuang JF, Hsu YP, Wang SY, Fu CY, Yuan KC, et al. Predictors of the development of post-snakebite compartment syndrome. Scand J Trauma Resusc Emerg Med. 2015 Nov 11;23:97-103.

19. Ho CH, Mao YC, Tsai YD, Lin CS, Liu SH, Chiang LC, et al. Descriptive study of snakebite patients in Northern Taiwan: 2009 to 2016. J Med Sci. 2019;39(3):114-20.

20. McQueen MM, Duckworth AD, Aitken SA, Court-Brown C. The estimated sensitivity and specificity of compartment pressure monitoring for acute compartment syndrome. J Bone Joint Surg Am. 2013 Apr;95(8):673-7.

21. Cumpston $\mathrm{KL}$. Is there a role for fasciotomy in Crotalinae envenomations in North America? Clin Toxicol (Phila). 2011 Jun;49(5):351-65.

22. Nakai M, Nakashima KI, Ogawa T, Shimohigashi Y, Hattori S, Chang $\mathrm{CC}$, et al. Purification and primary structure of a myotoxic lysine- 49 phospholipase A2 with low lipolytic activity from Trimeresurus gramineus venom. Toxicon. 1995 Nov;33(11):1469-78.

23. Dunbar JP, Sulpice R, Dugon MM. The kiss of (cell) death: can venominduced immune response contribute to dermal necrosis following arthropod envenomations? Clin Toxicol (Phila). 2019 Aug;57(8):677-85.

24. Bickler PE. Amplification of snake venom toxicity by endogenous signaling Pathways. Toxins. 2020 Feb;12(2):pii:E68.

25. Avau B, Borra $\mathrm{V}$, Vandekerckhove P, De Buck E. The treatment of snake bites in a first aid setting: a systematic review. PLoS Neglect Trop Dis. 2016 Oct 17;10(10):e0005079.

26. Gill Jr KA. Cryotherapy in the treatment of snake envenomation. Res Rep U S Nav Med Field Res Lab. 1968 Jul;18(9):1-15.

27. McKinney PE. Out-of-hospital and interhospital management of crotaline snakebite. Ann Emerg Med. 2001 Feb;37(2):168-74.

28. Cegolon L, Heymann WC, Lange JH, Mastrangelo G. Jellyfish stings and their management: a review. Mar Drugs. 2013 Feb;11(2):523-50.
29. Rojnuckarin $P$, Mahasandana $S$, Intragumthornchai $T$, Sutcharitchan $P$, Swasdikul D. Prognostic factors of green pit viper bites. Am J Trop Med Hyg. 1998;58(1):22-5

30. Jiménez N, Escalante T, Gutiérrez JM, Rucavado A. Skin pathology induced by snake venom metalloproteinase: acute damage, revascularization, and re-epithelization in a mouse ear model. J Invest Dermatol. 2008 Jun;128(10):2421-8.

31. Lin CC, Wang PJ, Liu CC. Venom concentrations in blisters and hemorrhagic bullae in a patient bitten by a Taiwan habu (Protobothrops mucrosquamatus). Rev Soc Bras Med Trop. 2019 Jan;52:e20180160.

32. Gnaneswaran N, Perera E, Perera M, Sawhney R. Cutaneous chemical burns: assessment and early management. Aust Fam Physician. 2015;44(3):135-9.

33. Chen CM, Wu KG, Chen CJ, Wang CM. Bacterial infection in association with snakebite: a 10-year experience in a northern Taiwan medical center. J Microbiol Immunol Infect. 2011 Dec;44(6):456-60.

34. Haverstock BD. Puncture wounds of the foot. Clin Podiatr Med Surg. 2012;29(2):311-22.

35. Villalta M, Pla D, Yang SL, Sanz L, Segura A, Vargas M, et al. Snake venomics and antivenomics of Protobothrops mucrosquamatus and Viridovipera stejnegeri from Taiwan: keys to understand the variable immune response in horses. J Proteomics. 2012 Oct 22;75(18):5628-45.

36. Mao YC, Hung DZ. Management of Snake Envenomation in Taiwan. Gopalakrishnakone P, Faiz MA, Fernando R, Gnanathasan CA, Habib AG, Yang CC, editor's. Clinical Toxinology in Asia Pacific and Africa. Singapore: Springer. p.23-52. 2015.

37. Ullah A, Souza TACB, Zanphorlin L, Mariutti RB, Santana VS, Murakami MT, et al. Crystal structure of Jararacussin-l: The highly negatively charged catalytic interface contributes to macromolecular selectivity in snake venom thrombin-like enzymes. Protein Sci. 2013 Jan;22(1):128-32.

38. Inn-Ho T, Ying-Ming W, Yi-Hsuan C, Tsai TS, Tu MC, et al. Venom phospholipases A2 of bamboo viper (Trimeresurus stejnegeri): molecular characterization, geographic variations and evidence of multiple ancestries. Biochem J. 2004 Jan 1;377(Pt 1):215-23.

39. Ouyang C, Teng CM, Huang TF. Characterization of the purified principles of Formosan snake venoms which affect blood coagulation and platelet aggregation. Taiwan Yi Xue Hui Za Zhi. 1982 Jul;81(7):781-90.

40. Ouyang C, Yang FY. Purification and properties of the thrombin-like enzyme from Trimeresurus gramineus venom. Biochim Biophy Acta. 1974 Jun 7;351(2):354-63.

41. Zhang Y, Gao R, Lee WH, Zhu SW, Xiong YL, Wang WY. Characterization of a fibrinogen-clotting enzyme from Trimeresurus stejnegeri venom, and comparative study with other venom proteases. Toxicon. 1998 Jan;36(1):131-42.

42. Ouyang C, Yang FY. The effects of the purified thrombin-like enzyme and anticoagulant principle of Trimeresurus gramineus venom on blood coagulation in vivo. Toxicon. 1976;14(3):197-201.

43. Chang MC, Huang TF. Characterization of a thrombin-like enzyme, grambin, from the venom of Trimeresurus gramineus and its in vivo antithrombotic effect. Toxicon. 1995 Aug;33(8):1087-98.

44. Ouyang $C$, Huang TF. a-and $\beta$-fibrinogenases from Trimeresurus gramineus snake venom. Biochim Biophys Acta. 1979 Dec 7;571(2):270-83.

45. Ouyang C, Yang FY. Purification and properties of the anticoagulant principle of Trimeresurus gramineus venom. Biochim Biophys Acta. 1975 Apr 29;386(2):479-92.

46. Huang $T F$, Chang $\mathrm{JH}$, Ouyang $\mathrm{C}$. Characterization of hemorrhagic principles from Trimeresurus gramineus snake venom. Toxicon. 1984;22(1):45-52.

47. Zhang Y, Wisner A, Xiong Y, Bom C. A novel plasminogen activator from snake venom Purification, characterization, and molecular cloning. J Biol Chem. 1995 Apr 28;270(17):10246-55.

48. Ouyang C, Huang TF. A potent platelet aggregation inducer from Trimeresurus gramineus snake venom. Biochim Biophys Acta. 1983 Dec 13;761(2):126-34.

49. Rucavado A, Soto M, Escalante T, Loría GD, Arni R, Gutiérrez JM. Thrombocytopenia and platelet hypoaggregation induced by Bothrops asper snake venom. Thromb Haemost. 2005;94(7):123-31. 
50. Levine M, Ruha AM, Padilla-Jones A, Gerkin R, Thomas SH. Bleeding following rattlesnake envenomation in patients with preenvenomation use of antiplatelet or anticoagulant medications. Acad Emerg Med. 2014 Mar;21(3):301-7.

51. Holla SK, Rao HA, Shenoy D, Bollor A, Boyanagari M. The role of fresh frozen plasma in reducing the volume of anti-snake venom in snakebite envenomation. Trop Doc. 2018 Feb 2;48(2):89-93.
52. Chen JC, Liaw SJ, Bullard MJ, Chiu TF. Treatment of poisonous snakebites in northern Taiwan. J Formos Med Assoc. 2000 Feb;99(2):135-9.

53. Gerardo CJ, Quackenbush E, Lewis B, Rose SR, Greene S, Toschlog EA, et al. The efficacy of Crotalidae polyvalent immune Fab (Ovine) antivenom versus placebo plus optional rescue therapy on recovery from copperhead snake envenomation: a randomized, double-blind, placebo-controlled, clinical trial. Ann Emerg Med. 2017 